\title{
A methodology approach for analysis of sustainability indicators as a tool for decision making using fuzzy logic
}

\author{
Á. L. G. Carneiro \& F. H. F. Quinhoneiro \\ Nuclear Energy Research Institute, \\ National Nuclear Energy Commission (IPEN/CNEN), Brazil
}

\begin{abstract}
The greatest challenge of this century is focused on sustainability due to, among other reasons, the world population growth and consequently an increase in demand of resources such as water, food and energy. The main difficulty when discussing the issue of sustainable development is the evaluation methodology. Therefore, there is a need for a measurement tool that addresses these resources in a holistic manner and be able to translate data into results that can be interpreted in an easy way. There are tools validated for this purpose like: "Dashboard of Sustainability", "Barometer of Sustainability" and others under development such as the CLEW Nexus by the International Atomic Energy Agency (IAEA). This paper aims to develop a new model to analyze the correlation between the variables, energy, water, land use and climate, using artificial intelligence through fuzzy logic, having as a database, indicators that represent one or more resource, considering the relative and temporal distribution required to research results and behaviors. The result is a final index generated by mapping these input data. The results presented in this paper refer to an analysis of Brazilian indicators, although they can be applied to any other country, allowing a comparison analysis of the behavior of index between regions. The contribution of this project is the availability of a tool with powerful computational resource, aimed at decision makers to assist in developing strategies and development policies.
\end{abstract}

Keywords: sustainability indicators, decision making, fuzzy logic. 


\section{Introduction}

Nowadays the most important issues discussed around the world are related to sustainability. The topic sustainable development in the late $80 \mathrm{~s}$, became recognized in the intergovernmental sphere, with the publication of the Brundtland Report [1], which defines "Sustainable Development as the one that meets present needs, without compromising the ability of future generations to meet their own needs". This publication addresses theme development in a holistic context, integrating the economic, social and environmental dimension, incorporating later at the beginning of this century the institutional dimension.

The main difficulty when discussing the issue of sustainable development is the methodology for assessment of such development [2]. Hence the need to create measurement tools, or indicators of development that are comprised of one or more variables that are associated through several forms, reveal broader meanings of the phenomena to which they refer.

The process of developing analysis methodology comes contributing to a better understanding of sustainable development, always focusing on the changing in global trends that today can be summarized as the need for a more dynamic vision that involves global risks, problems of population growth and urbanization, sharpening of socioeconomic duality, disruptions and technological discontinuities and inter-generational consciousness.

Among the various aspects of the development, we can say that the energy problem is not only the vital points in the evaluation of development but as regards as sustainability.

As pronounced by the United Nations "2012 International Year - Energy for All", as goal by 2030 to ensure universal access to modern energy [3].

The United Nations emphasize the need to double the rate of energetic improvement and increasing the share of renewable energy to make energy systems sustainable, otherwise there is a probability of a collapse occurs.

The International Atomic Energy Agency, in the publication Nuclear Technology Review 2009, entitled, "Seeking Sustainable Climate, Land, Energy and Water (Clew) Strategies" [4], highlights the problem of global demand growth, with scarce resources such as land, water and energy, and how the use of each of these features affects the demand of others and that consequently the use of all of them affects the climate and the environment. Showing evidence of interdependence between resources, and the importance of these considerations, when it comes to the development of strategies and policies, which should developed in an integrated manner, not separately $[5,6]$.

Therefore, it is necessary to develop modeling and analysis methodologies that make it possible to process a universe of information and data with their respective correlations, translating into interpretable, providing a tool to assist decision makers. 


\section{Fuzzy logic}

In the mid-60s, Prof. Zadeh, creator of fuzzy logic, observed that the available technological resources were incapable to automate the activities related to problems of industrial nature, biological or chemistry, that understand ambiguous situations, not amenable to processing by computer based on Boolean logic [7].

The basic difference between classical logic and fuzzy logic is that conventional logic treats concepts as discrete categories and fuzzy logic can simultaneously assign the same concept several linguistic values associated with degrees of certainty.

\subsection{Fuzzy set operations}

Fuzzy logic is based on fuzzy sets, an extension of classical set theory. With fuzzy logic technique a computer is able to process words from natural language, such as 'low', 'high', and 'almost the same', into a numerical output [8, 9].

Fuzzy set "A" can be written in ordered pairs as:

$$
\mathrm{A}=\left\{\left(\mathrm{x}, \mu_{\mathrm{A}}(\mathrm{X})\right) \mid \mathrm{x} \in \mathrm{X}\right\}
$$

There are several possible generalization of this classical set theory. The most used operation is the standard fuzzy set operation. There are three operations: fuzzy complements, fuzzy intersections, and fuzzy unions.

$$
\begin{array}{ll}
\text { Union: } & \mu_{A \cup B}(x)=\mu_{A}(x) \vee \mu_{B}(x) \\
\text { Intersection: } & \mu_{A \cap B}(x)=\mu_{A}(x) \wedge \mu_{B}(x) \\
\text { Complement: } & \mu_{\bar{A}}(x)=1-\mu_{A}(x)
\end{array}
$$

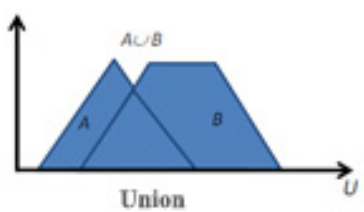

Union

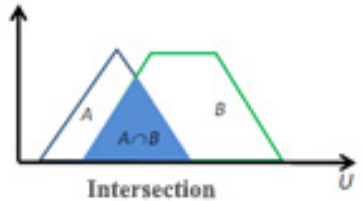

Intersection

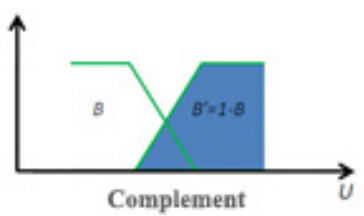

Figure 1: Operations of a classical set.

The fuzzy sets are a "bridge" in the path of approaching human reasoning to the logic performed by the machine.

\subsection{Linguistic variable}

Linguistic variable is the name that is given to a fuzzy set. For example, the height of a person can assume the values low, medium or high. 


\subsection{Membership function}

A membership function is a curve that defines how each point in the universe of discourse is mapped to a value that represents the membership degree of this input to a fuzzy set that can assume values between 0 and 1 .

Therefore, the membership of "X" to a fuzzy set "A" can be written as:

$$
\mu_{\mathrm{A}}: \mathrm{X} \rightarrow[0,1]
$$

where $\mu_{\mathrm{A}}$ is the membership degree.

There are different types of membership function:

- Triangular

- Trapezoidal

- Gaussian

- Generalized bell

- $\quad$ Sigmoid

As shown in the previous example of the height of a person, the universe of discourse of a set "tall people" (linguistic variable) is composed by all the possible heights from 3 feet to 9 feet.

Figure 2 presents the steps that comprise the process of fuzzy reasoning or fuzzy architecture.

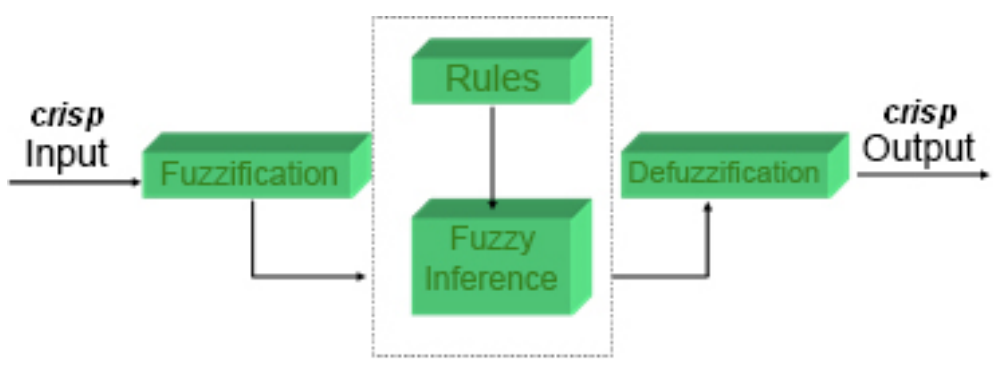

Figure 2: Fuzzy modeling.

Fuzzification: Comprises the step in which linguistic variables (input variables) are defined subjectively, as well as member functions (membership functions). This phase of the process comprises:

- Analysis of the problem

- Definition of variables

- Definition of membership functions (triangular, trapezoidal, etc.)

- Creation of regions

Rules Base: The key mechanism of the fuzzy model is the proposition that is the relationship between the variables of the model and fuzzy regions.

To build these propositions you should work with:

a. Conditional propositions: if $\mathrm{W}$ is $\mathrm{Z}$ then $\mathrm{X}$ is $\mathrm{Y}$;

b. Non-conditional propositions: $\mathrm{X}$ is $\mathrm{Y}$. 
The aggregation calculates the importance of a given rule to the current situation and the composition calculates the influence of each rule in the output variables. The informal language descriptions used by human (expert) on a daily is the starting point for the development of inference rules.

Inference: is the stage in which the propositions (rules) are examined at the same time. The inference device is an algorithm that consists in a computational treatment of a set of "rules" that represents the knowledge of an expert.

This phase includes:

- Definition of propositions;

- Analysis of the rules:

- Creation of the resulting region

Defuzzification: the third step of the process, where the resulting areas are converted into values to the output variables of the system. This step corresponds to the functional link between fuzzy regions and the expected value.

The main types of defuzzification methods are:

- Centroid (that is used in this case)

- Bisector

- $\quad$ Middle, Smallest, and Largest of Maximum

The Centroid method: numerical control action is calculated by obtaining the center of gravity of the distribution possibilities of global control, as follow.

$$
U=\frac{\int_{\operatorname{Min}}^{\operatorname{Max}} u \mu(u) d u}{\int_{\operatorname{Min}}^{\operatorname{Max}} \mu(u) d u}
$$

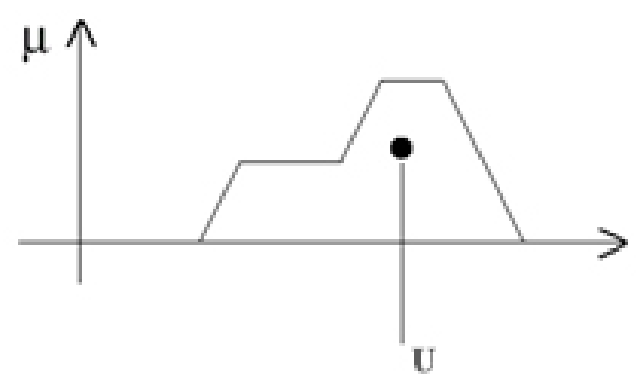

Figure 3: Defuzzification by centroid method.

Figure 4 represents a complete fuzzy modeling, with two inputs, two rules and defuzzification by centroid method.

We can define fuzzy logic as a tool capable of capturing vague information, generally described in a natural language and convert it to a numeric format, for easy manipulation in computer language. 


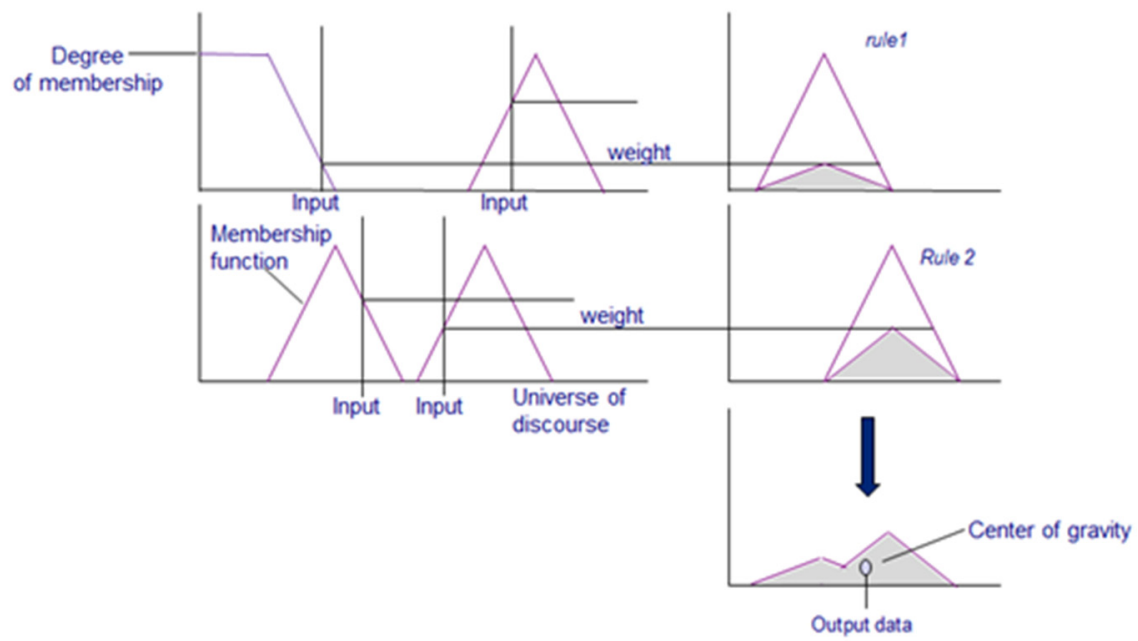

Figure 4: Fuzzy modeling with two inputs, two rules and one output.

\section{$3 \quad$ Fuzzy modeling}

The selected indicators follow the modeling showed in Figure 1, relating to resources that represent the input variables of the system, being presented generically as three macro variables for each resource, Climate, indicators IC1, IC2 and IC3; Water, indicators IA1, IA2 and IA3; Land Use, indicators IS1, IS2 and IS3 and Energy, indicators IE1, IE2 and IE3.

The 1st order fuzzy modeling generates the output indicators corresponding to each group of variables, IC, IA, IS and IE.

The last step, 2nd order fuzzy modeling, is the result of all processing and correlation of IC, IA, IS and IE variables, translated into a hypothetical index called Icase.

The work has been developed using the platform MATLAB, using the Fuzzy Logic Toolbox package, from MathWorks.

\section{Database}

The database consists in indicators that represent one or more resources, considering a temporal relative distribution of ten years. These data provide information on use of natural resources, environmental quality, satisfaction of human needs, quality of life and social justice, macroeconomic and financial performance, energy use, well as on the capacity and institutional efforts conducted seeking the necessary changes for the implementation of sustainable development. 

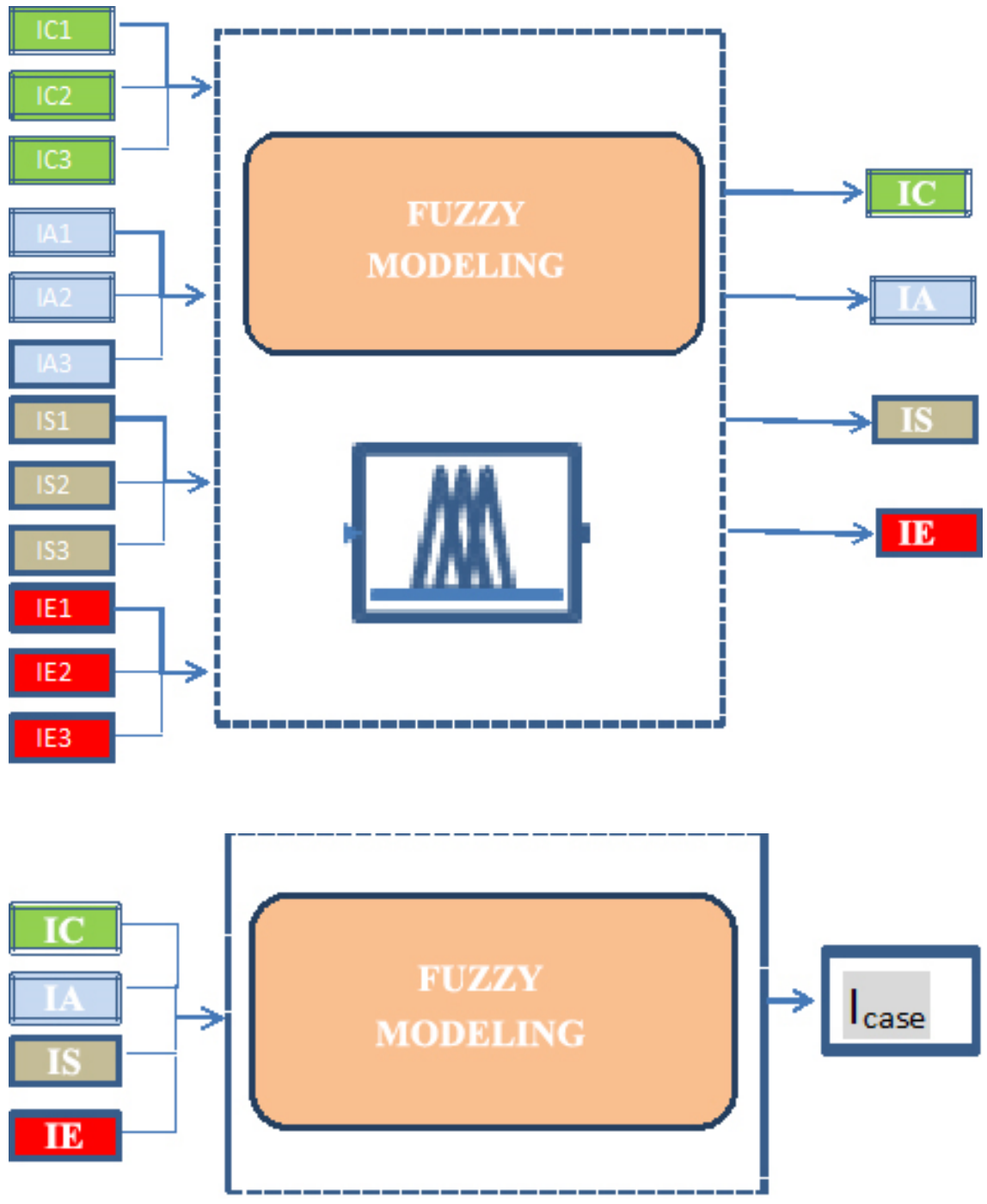

Figure 5: Fuzzy modeling, $1^{\text {st }}$ and $2^{\text {nd }}$ order.

This information is valuable for understanding the relevant issues to the country's development, allowing knowing the direction and the pace of its various elements, by comparison, and make an integrated judgment from different approaches and dimensions, fundamental to the proper formulation and evaluation of policies in the perspective of sustainable development.

The indicators that composes the input variables of the resources that will be analyzed are presented in Table 1. 
Table 1: Selected indicators.

\begin{tabular}{|c|c|}
\hline Resource & Input Variables \\
\hline Climate & $\begin{array}{l}\text { IC1: Emission of Greenhouse Gases } \\
\text { IC2: Emission of Gases Destroyers of the Ozone } \\
\text { Layer } \\
\text { IC3: Fire Outbreaks }\end{array}$ \\
\hline Water & $\begin{array}{l}\text { IA1: Number of Households with Access to Water } \\
\text { Supply } \\
\text { IA2: Maritime and Continental Fish Production } \\
\text { IA3: Useful volume of Major Reservoirs }\end{array}$ \\
\hline Land Use & $\begin{array}{l}\text { IS1: Planted Area with Sugarcane } \\
\text { IS2: Annual gross deforestation in the Amazon } \\
\text { IS3: Fertilizer Use }\end{array}$ \\
\hline Energy & $\begin{array}{l}\text { IE1: Participation of Renewable Sources } \\
\text { IE2: Energy Intensity } \\
\text { IE3: Energy Consumption per Capita }\end{array}$ \\
\hline
\end{tabular}

\section{Results analysis}

The application of fuzzy logic technique to the implementation of this methodology became possible to obtain one indicator that represents each of the resources and the interactions among their variables. These indicators are IDC (indicator of climate development), IDA (indicator of water development), IDS (indicator of land use development) and IDE (indicator of energy development).

The increase of the subsets on the fuzzy architecture, from three to five, ensures the most reliable results, since a greater number of rules have been activated during the process of inference, giving the system a greater computational power.

The first results obtained were the behavior of those resources in the analyzed period, Table 2.

The indicators that represent the resources of Climate (IC), Water (IA) and Energy (IE), presents growth in the analyzed period, showing an evolution in the management of these resources.

In the case of climate resource, this growth is due to improvement in fire monitoring and implementation of new laws that has entered into force during this period. The indicator water had as main driver of its results the increasing number of households with water supply, and the improvement in the useful volume of the main reservoirs in this period. 
Table 2: Results of the $1^{\text {st }}$ order fuzzy modeling.

\begin{tabular}{ccccc}
\hline & IC & IA & IS & IE \\
\hline $\mathbf{2 0 0 0}$ & 0.499 & 0.142 & 0.618 & 0.476 \\
$\mathbf{2 0 0 1}$ & 0.492 & 0.224 & 0.621 & 0.531 \\
$\mathbf{2 0 0 2}$ & 0.333 & 0.504 & 0.499 & 0.546 \\
$\mathbf{2 0 0 3}$ & 0.400 & 0.507 & 0.333 & 0.555 \\
$\mathbf{2 0 0 4}$ & 0.333 & 0.666 & 0.418 & 0.583 \\
$\mathbf{2 0 0 5}$ & 0.499 & 0.666 & 0.586 & 0.649 \\
$\mathbf{2 0 0 6}$ & 0.775 & 0.607 & 0.587 & 0.707 \\
$\mathbf{2 0 0 7}$ & 0.531 & 0.775 & 0.469 & 0.643 \\
$\mathbf{2 0 0 8}$ & 0.806 & 0.819 & 0.391 & 0.562 \\
$\mathbf{2 0 0 9}$ & 0.872 & 0.872 & 0.499 & 0.665 \\
$\mathbf{2 0 1 0}$ & 0.665 & 0.858 & 0.377 & 0.626 \\
\hline
\end{tabular}

The indicator that measures the energy development presented a very low growth. Among the three variables that comprise this indicator two of then presented an evolution due the improvement of energy intensity and increasing the share of renewable sources in energy consumption in the country. The variable responsible for the decrease of this growth was the increased consumption of energy per capita, which is a result of the growth of the country from 2000 to 2010, since the power consumption accompanying the increase of GDP.

The only indicator that presented regression was the IS due to the growth of the amount of fertilizers used and the exponential growth of the area used for growing sugarcane.

These indicators of each resource, Climate, Water, Land Use and Energy, composes the input data of the 2nd order fuzzy modeling, responsible for mapping this information into an output index called CASE ( $\mathrm{I}_{\mathrm{CASE}}$ ), that will be used to measure and analysis the sustainability process in Brazil based on the studied resources.

According to the $\mathrm{I}_{\mathrm{CASE}}$ obtained, there was continued growth of sustainable development in Brazil, due to the indicators of Climate, Water and Energy, with negative and positive peak in 2003 and 2006 respectively.

\section{Conclusion}

The greatest difficulty in measuring something as sustainability in a country or region is the lack of a tool that can unify multiple variables, considering all its interdependencies. Therefore in this project, were considered the main resource that must be used conscientiously ensuring that future generations can enjoy these goods and resources. 


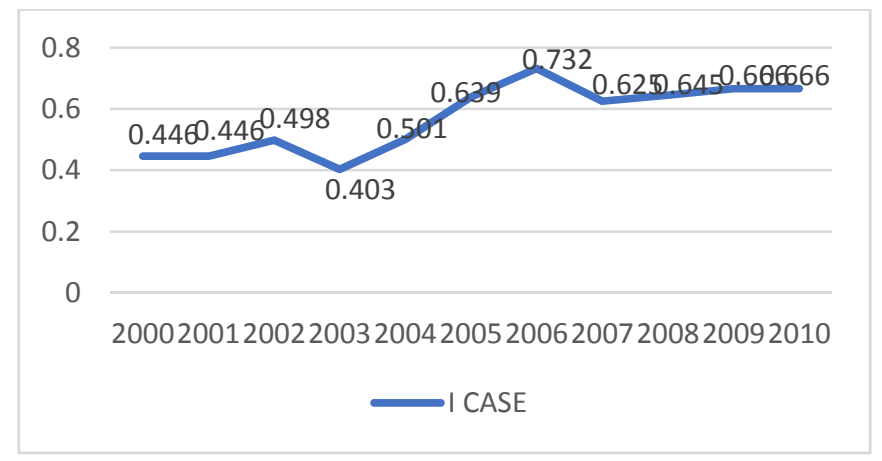

Figure 6: Results of the $2^{\text {nd }}$ order fuzzy modeling.

Hence, the need to develop public policies that direct the actions in Brazil, not allowing the uncontrolled and thoughtless use of these resources may impair their availability, since the demand for them is increasing due to population growth.

This tool shows the temporal evolution of sustainable development in Brazil, and enable us to make a retrospective analysis of this index every year and all the variables, assisting decision makers in the development of public policies.

These variables separately cannot explain sustainability as a whole, but when analyzed in a holistic manner reveal a broader meaning of this phenomenon.

\section{References}

[1] Brundtland, Gro Harlem. Nosso Futuro Comum. Editora da FGV, 1987. "Our Common Future", Oxford: Oxford University Press, 1987.

[2] IAEA, 2005. Indicators of Sustainable Development: Guidelines and Methodologies, 2nd. Edition, September. New York, NY, USA: United Nations Department of Economic and Social Affairs.

[3] IEA, 2010a. Energy Technology Perspectives 2010: Scenarios and Strategies to 2050. IEA/OECD, Paris.

[4] IAEA (International Atomic Energy Agency). 2009. Annex VI: Seeking Sustainable Climate Land Energy and Water (CLEW) strategies, Nuclear Technology Review 2009.

[5] Morgan Bazilian, Holger Rogner, Mark Howells, Sebastian Hermann, Douglas Arent, Dolf Gielen, Pasquale Steduto, Alexander Mueller, Paul Komor, Richard S.J. Tol, Kandeh K. Yumkella; Considering the energy, water and food nexus: Towards an integrated modelling approach, Energy Policy, 2011.

[6] H.H. Rogner, Climate, Land, Energy and Water Strategies, in: 2009.

[7] Zadeh, L. A. Fuzzy Sets-Information and Control 8, pp. 338-353 (1965).

[8] Ross, Timothy J., Fuzzy Logic with Engineering Applications, John Wiley \& Sons, 2004.

[9] Yen, J.; Langari, R. Fuzzy logic: intelligence, control, and information. Prentice Hall, Upper Saddle River, NJ, USA, 1999. 